\title{
Early dihydrofolate reductase gene amplification events in CHO cells usually occur on the same chromosome arm as the original locus
}

\author{
Barbara J. Trask ${ }^{1}$ and Joyce L. Hamlin ${ }^{2,3}$ \\ ${ }^{1}$ Biomedical Sciences Division, Lawrence Livermore National Laboratory, Livermore, California 94550 USA; ${ }^{2}$ Department of \\ Biochemistry, University of Virginia School of Medicine, Charlottesville, Virginia 22908 USA
}

\begin{abstract}
We used fluorescence in situ hybridization to examine the products of early DNA sequence amplification events in CHO cells. Nine independent populations of cells were selected for resistance to $0.4 \mu \mathrm{M}$ methotrexate (MTX), and mitotic chromosome spreads were hybridized to a mixture of cloned cosmids representing $\sim 273 \mathrm{~kb}$ of contiguous DNA sequence from the dihydrofolate reductase (DHFR) locus. Of the nine populations, eight contain cells that have amplified the DHFR domain. Cells in the remaining population displayed only the two single-copy loci on chromosomes 2 and $\mathrm{Z2}$. Of the eight amplificants, one carries amplified DHFR genes on chromosome 2 , six on chromosome $\mathrm{Z2}$, and one on an unidentified chromosome. Some cultures carry additional amplified genes on other chromosomes, probably resulting from bridge/breakage/fusion cycles or translocations. In six of the eight amplificants, both single-copy parental loci are detected at their original positions, and amplicon clusters are situated at least 50 megabases $(M b)$ away on the same chromosome arm, often at the termini. Amplification occurred at or close to the original site of the DHFR gene in only one population. Our results are not consistent with models in which initial amplification events occur by over-replication of the parental locus followed by recombination in loco. Because amplified DHFR sequences occur most often on the same chromosome arm as the parental DHFR gene but at a considerable distance from it, our results are most compatible with either sister chromatid exchange between widely separated sites or with a form of conservative intrachromosomal duplication analogous to transposition in bacteria.
\end{abstract}

[Key Words: Dihydrofolate reductase; $\mathrm{CHO}$ cells; gene amplification]

Received August 10, 1989; revised version accepted September 28, 1989.

The genomes of tumor cells are known to display many different gross anomalies, including abnormal ploidy, translocations, inversions, ring chromosomes, abnormally banding chromosome regions, and double minute chromosomes (Levan et al. 1977; Yunis 1981). The latter two structural variants have been shown to result from the localized amplification of a portion of the genome (for review, see Cowell 1982; Hamlin et al. 1984; Schimke 1984, 1988; Stark and Wahl 1984; Stark 1986). Studies on various tumor cell lines that are resistant to different chemotherapeutic agents have demonstrated that resistance is most often the result of amplification of genes encoding either the respective target enzymes or proteins involved in drug efflux (for review, see Hamlin et al. 1984; Schimke 1984, 1988; Stark and Wahl 1984; Stark 1986). Moreover, several different oncogenes have been shown to be amplified in a variety of human tumors and established tumor cell lines (for review, see Bishop 1987). Thus, DNA sequence amplification is a phenomenon with important clinical consequences.

${ }^{3}$ Corresponding author.
A study of initial amplification events is desirable to understand the mechanism(s) responsible for DNA sequence amplification. However, this has proved to be a difficult task, as the frequency of amplification of a particular selectable locus is typically only $10^{-4}$ to $10^{-5}$ per cell generation (Zieg et al. 1983; Stark and Wahl 1984; B. Trask and J. Hamlin, unpubl.). Amplification frequency can be increased by subjecting cells to a variety of insults, including UV light (Tlsty et al. 1984), carcinogens (Lavi 1981), phorbol esters and hormones (Varshavsky 1981; Barsoum and Varshavsky 1983), and drugs that interfere with DNA replication (Brown et al. 1983), but it has not yet been possible to induce the amplification of a particular marker in all cells in a population within a single cell cycle. In addition, the mechanisms responsible for amplification under these inductive circumstances may not be the same as those responsible for the spontaneous amplification of oncogenes or drug-resistance markers in human tumors.

We and others have taken a second approach, which is to examine the actual sequence and chromosomal rearrangements that have occurred in the genomic DNA of 
cell lines bearing amplified genes (Tyler-Smith and Bostock 1981; Caizzi and Bostock 1982; Ardeshir et al. 1983; Zieg et al. 1983; Federspiel et al. 1984; Roninson et al. 1984; Debatisse et al. 1986; Giulotto et al. 1986; Kinzler et al. 1986; Borst et al. 1987; Hyrien et al. 1987; Looney and Hamlin 1987; Looney et al. 1988; Ma et al. 1988). The aim is to determine whether the observed end products can support or eliminate particular models for DNA sequence amplification.

In the present study, we examined the chromosomal manifestations of methotrexate (MTX) resistance by hybridizing a series of cloned probes from the Chinese hamster dihydrofolate reductase (DHFR) domain (Looney and Hamlin 1987) to mitotic chromosome spreads. We have taken advantage of the high sensitivity and resolution attainable using biotinylated hybridization probes and fluorescein-labeled avidin for detection. This method allows single-copy sites to be detected with high efficiency (Trask et al. 1989). The results of an analysis of four highly MTX-resistant clonal cell lines and nine independently derived moderately resistant cell populations argue against certain models for DNA sequence amplification and suggest other alternatives.

\section{Results}

\section{Fluorescence in situ hybridization allows visualization of single-copy DHFR loci}

To demonstrate the efficiency with which single-copy DHFR loci can be detected, metaphase spreads were prepared from drug-sensitive $\mathrm{CHO}-\mathrm{K} 1$ cells and were hybridized to a pool of eight biotinylated cosmids representing $273 \mathrm{~kb}$ of contiguous DNA sequence in the Chinese hamster DHFR locus (Looney and Hamlin 1987). In addition to the DHFR gene itself, a second transcription unit (2BE2121; Foreman and Hamlin 1989), a matrix attachment site (Dijkwel and Hamlin 1988), and two replication-initiation loci have been mapped in this domain (Heintz and Hamlin 1982; Anachkova and Hamlin 1989; Leu and Hamlin 1989). An example of the signals obtained from the two DHFR loci in CHO-K1 cells after detection of DHFR-specific hybridization with fluores- ceinated avidin are shown in Figure 1A. In Figure 1B, the chromosomes are arranged according to size and are tentatively identified by the convention of Worton (1978). Clear fluorescent signals were observed on both chromatids of chromosome 2 and on its rearranged partner, Z2 (Deaven and Peterson 1973) at a position about onethird of the way out from the centromere on the homologous $2 q$ arms. Note that the intensities of fluorescent signals are similar among the four single-copy sites within a given cell. Chromosomes 2 and $\mathrm{Z} 2$ were labeled in $100 \%$ of $395 \mathrm{CHO}-\mathrm{K} 1$ metaphase cells analyzed.

Patterns of amplification of the DHFR domain in four independently selected highly MTX-resistant Chinese hamster cell lines

We determined the chromosomal locations of the DHFR domains in four independently isolated, highly MTX-resistant Chinese hamster cell lines. The clonal cell lines studies were MK42 (Nunberg et al. 1978), A3/4K [a more resistant variant of the DC3F/A3 cell line (Biedler and Spengler 1976)], CHOC 400 (Milbrandt et al. 1981), and B11-0.5K1 (Kaufman and Schimke 1981). These cell lines have been estimated to contain $\sim 150$ (Nunberg et al. 1978), 500 (J. Hamlin, unpubl.), 1000 (Milbrandt et al. 1981), and 50 (Kaufman and Schimke 1981) copies of the DHFR gene, respectively. MK42, CHOC 400, and B11-0.5K1 are derivatives of $\mathrm{CHO}$ cells, and the $\mathrm{A} 3 / 4 \mathrm{~K}$ cell line was derived from a Chinese hamster lung fibroblast.

Intense fluorescent staining was detected over the same chromosomal regions that have been shown previously to contain amplified DHFR genes by G-banding and hybridization to radiolabeled probes (Fig. 2; Biedler and Spengler 1976; Nunberg et al. 1978; Kaufman and Schimke 1981; Milbrandt et al. 1981). However, the increased sensitivity of the fluorescence hybridization method allowed the detection of single-copy sites in addition to the zones of amplification.

Both parental single-copy loci were detected at their original chromosomal locations on chromosomes 2 and Z2 in the MK42 cell line (Fig. 2A). The amplicon cluster in MK42 is located $10-20 \mathrm{Mb}$ distal to the single-copy
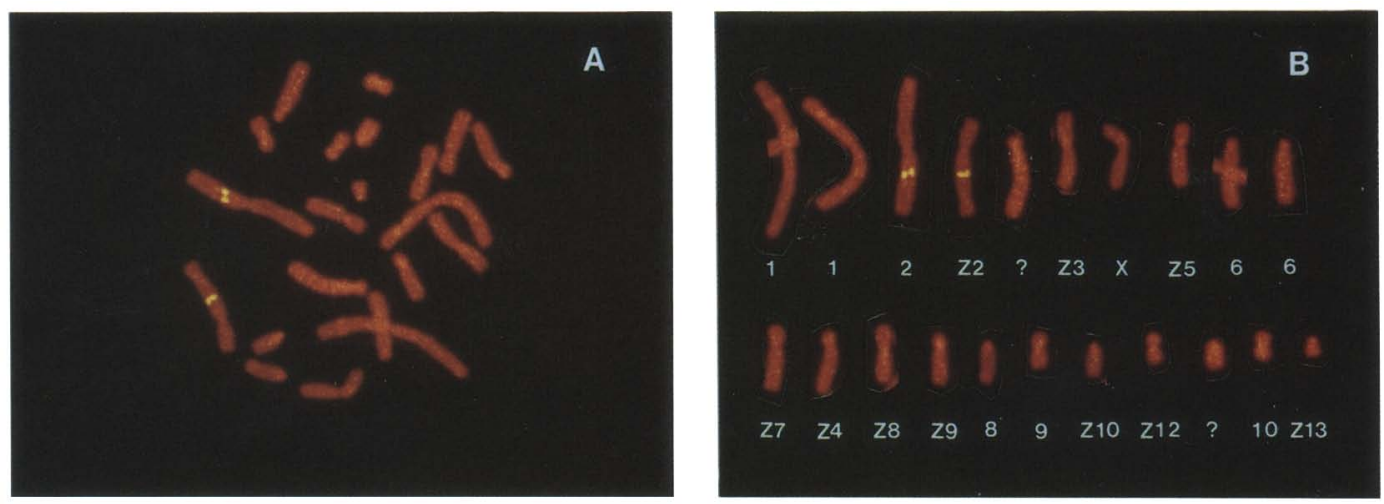

Figure 1. Diploid CHO-Kl cells after fluorescence in situ hybridization with probes from the DHFR locus. $(A)$ Metaphase cell. $(B)$ Metaphase chromosomes arranged by size and identified tentatively by the convention of Worton (1978). (Yellow) Sites of hybridization of biotinylated probes detected with fluorescein-avidin; (red) propidium iodide staining of DNA. 

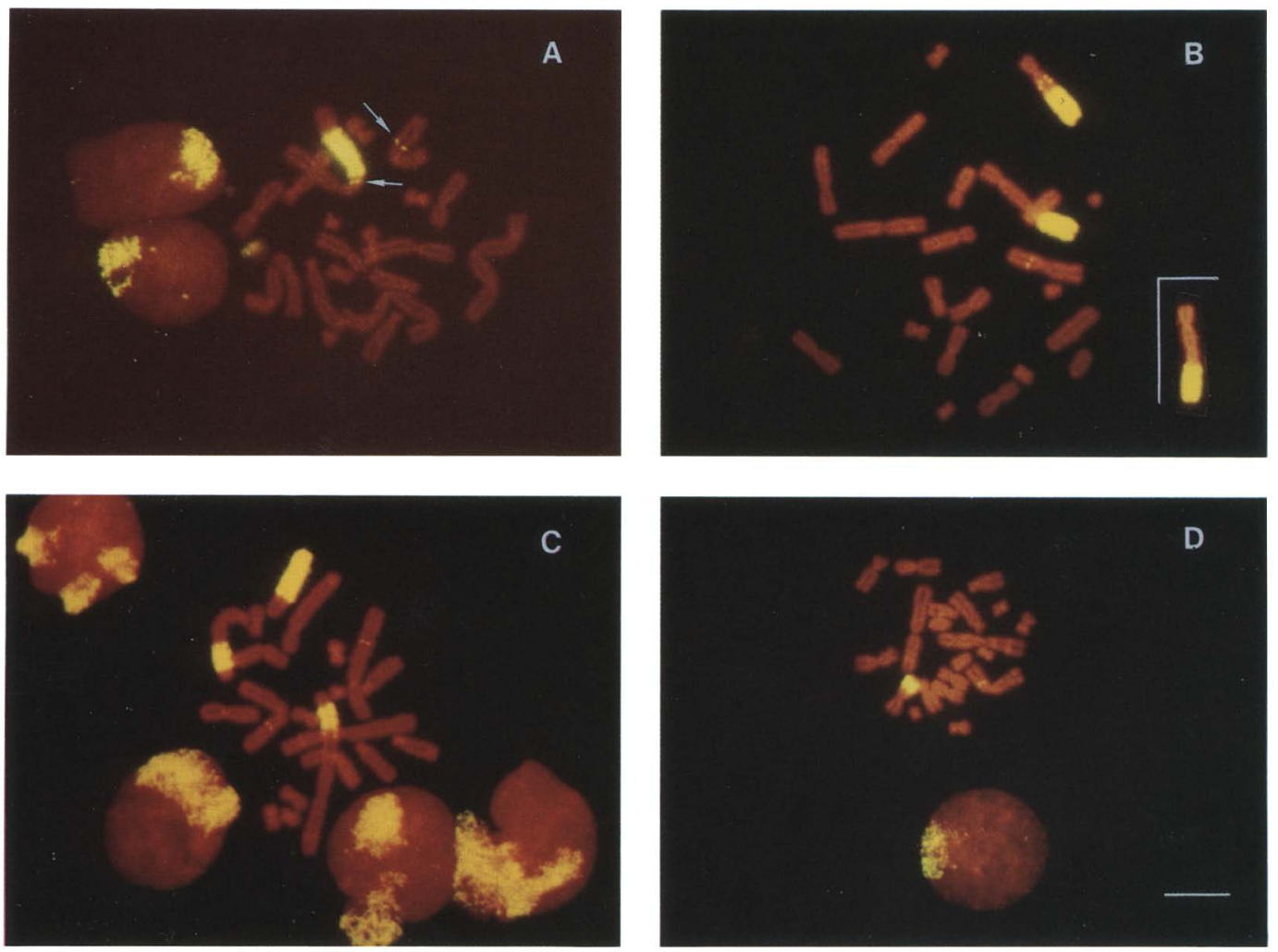

Figure 2. Metaphase cells of four different highly MTX-resistant cell lines after fluorescence in situ hybridization with DHFR locus probes. $(A-D) \mathrm{MK} 42, \mathrm{~A} 3 / 4 \mathrm{~K}, \mathrm{CHOC} 400$, and B11-0.5K1, respectively. Arrows in $A$ indicate single-copy sites. A photograph of the marker chromosome from a second metaphase $\mathrm{A} 3 / 4 \mathrm{~K}$ cell is shown in the insert to $B$, because it overlaps another chromosome in the cell shown. $(D)$ Bar, $10 \mu \mathrm{m}$.

site on chromosome 2 [using $380 \mathrm{Mb}$ as an estimate of the DNA content of chromosome $\mathrm{Z} 2$ (Deaven and Peterson 1973; Funanage and Myoda 1986)]. The A3/4K cell line (Fig. 2B) retains a single-copy site on chromosome 2 and has two other sets of apparently single-copy sites between the centromere and the terminal amplicon cluster on a large marker chromosome [probably a rearranged 2 (Biedler 1982)]. An additional chromosome, which is stained on the distal half of its long arm with the DHFR-specific probes, is observed in the A3/4K cell line. This chromosome was apparently generated by breakage and translocation of the original marker chromosome observed by Biedler and Spengler after additional amplification during selection in higher MTX concentrations in our laboratory.

In CHOC 400 cells (Fig. 2C), single-copy loci were detected on chromosome 2 and on a rearranged version of chromosome $\mathrm{Z2}\left(\mathrm{Z2}^{\prime}\right)$ that is unique to the starting $\mathrm{CHO}$ cell line from which $\mathrm{CHOC} 400$ was derived. This rearrangement apparently occurred several years ago during propagation of $\mathrm{CHO}$ cells in our laboratory. Amplicon clusters are present on three chromosomes: $1, \mathrm{Z} 4$, and a marker. Two small zones of DHFR-specific staining (possibly single copy) were also observed proximal to the main amplicon cluster on the long arm of chromosome
1. The latter chromosome was the first detectable site of amplification in the genesis of this cell line (C. Ma and J.L. Hamlin, unpubl.). During the development of the CHOC 400 cell line, it is likely that the $2 q$ end of the original $\mathrm{Z2}^{\prime}$ chromosome underwent a reciprocal translocation with chromosome 1 either before, concomitant with, or after the acquisition of the first amplified copies of the DHFR domain (Ma et al. 1988). Note that the amplicon clusters appear to bulge out from the rounded periphery of the interphase nuclei in Figure 2C, suggesting that the amplified DNA in this cell line may not be packaged correctly in the nucleus. B11-0.5K1 (Fig. 2D) is the only one of the four highly resistant cell lines analyzed in which the major site of amplification appears to be located at or close to the original site of the parental gene, in this case on the truncated $2 q$ arm of chromosome Z2.

Variant karyotypes were also found in all four highly resistant cell lines. The fractions of cells of MK42, $\mathrm{A} 3 / 4 \mathrm{~K}$, CHOC 400, and B11-0.5K1 with amplification patterns different from those shown in Figure 2 are 0.06 , $0.15,0.27$, and 0.05 , respectively. These variants represent rearrangements of the most common pattern discussed above, probably resulting from fragmentation, translocation, and bridge/breakage/fusion cycles (B. 
Trask, in prep.). These events are similar to those observed in the moderately resistant cell populations discussed below.

\section{Analysis of moderately resistant Chinese hamster ovary cell populations}

The results of in situ hybridization studies on the four highly MTX-resistant cell lines suggested that (1) both parental loci are usually retained after amplification, and (2) the DHFR amplicon clusters are usually on the same chromosome arm as one of the parental loci, but at a distance from it. To determine the generality of these observations, we selected nine additional MTX-resistant cell populations. To increase the likelihood that each population arose from independent initial events, a single drug-sensitive $\mathrm{CHO}-\mathrm{K} 1$ cell was cloned, expanded, and distributed into nine plates. Cell populations resistant to $0.4 \mu \mathrm{M}$ MTX were developed in each plate after two selection steps, and mitotic cells were collected for hybridization analysis within 6-8 weeks of initial exposure to MTX (see Experimental methods). No attempt was made to isolate individual clones at each step. In this way, we could examine as many initial amplification events as possible and would reduce the chances of selecting against any unstable variants during the time period required to expand single clones.

Two examples of the fluorescent staining patterns observed in each of the nine populations are shown in Figure 3. Chromosomes that hybridized with the probe were classified when possible according to size and centromere location using propidium iodide counterstaining. The positions of single-copy sites and/or amplicon clusters relative to the centromeres and telomeres in these chromosomes were determined for a number of chromosomes in each population and are summarized in the sketches in Figure 4. The frequencies of each type in the nine individual populations are indicated. Every mitotic spread that we examined is represented in Figure 4, whereas the karyotypes shown in Figure 3 were chosen to illustrate selected features discussed below.

Population A Of 20 cells examined in population A (Fig. 3A1,A2), 11 probably arose from the same initial amplification event, because their karyotypes have the following features (Figs. 3Al and 4A): (1) single-copy sites on both chromosomes 2 and Z2 (although the latter seems to be truncated; cf. the $2 q$ arms in 2 and Z2); (2) a possible ring that carries multiple copies of the DHFR gene in patchy clusters, which may represent the broken off end of Z2; and (3) a metacentric chromosome (possibly X) carrying a few copies of the DHFR amplicon. Three cells in population A are missing chromosome 2, have one parental single-copy locus on $\mathrm{Z} 2$, and show a relatively large patch of fluorescence on an unidentified marker chromosome (Figs. 3A2 and 4A). The remaining six cells examined contain only the two single-copy loci.

Population B Of 57 cells examined in this culture, 55 contained only the two single-copy loci on chromosomes 2 and Z2 (not shown). The other two cells contain two copies of Z2 and one copy of chromosome 2.

Population C Population C (Fig. 3C1,C2) is the only culture in which amplification has occurred on chromosome 2 . The single-copy DHFR loci on this chromosome and on chromosome $\mathrm{Z} 2$ are retained at their native sites. In many cells, chromosome 2 shows more than one band of amplification (e.g., Fig. 3C1). In almost all cases, the nearest amplicon cluster is closer to the telomere than it is to the single-copy locus (Fig. 4). In $45 \%$ of cells examined, the amplicon cluster extends to the telomere. In many cells, the centromere-proximal edge of the amplicon cluster is farther from the single-copy DHFR locus than the telomere is in the nonrearranged chromosome. In the mitotic cell shown in Figure $3 \mathrm{C} 2$, chromosome 2 is attached near a DHFR amplicon cluster to the end of chromosome 1. This suggests that breakage occurred within an amplicon cluster and that the broken end of chromosome 2 then somehow became joined to chromosome 1. At a subsequent mitosis, this dicentric chromosome would be subject to breakage, probably somewhere between the two centromeres. If this occurred within the amplicon cluster, two chromosomes would then bear DHFR amplicons at terminal locations. If the break occurred in such a way as to transfer the amplicon cluster entirely to chromosome 1, one could conclude mistakenly that the original amplification event occurred on chromosome 1 . Occasional tetraploids were also observed in this population (Fig. 4C). In one of these, translocation of some of the DHFR amplicons from the $q$ to the $p$ terminus of chromosome 2 appears to have occurred.

Population D Population D (Fig. 3D1,D2) is the only one in which the amplicon clusters are situated very close to or at the site of the parental DHFR locus on chromosome $\mathrm{Z} 2$. In $60 \%$ of the cells, the amplified region extends to the telomere. Figure $3 \mathrm{Dl}$ shows portions of three metaphase cells. Most of the figures observed in this culture can be interpreted as derivatives of a single starting amplificant that underwent different modifications in individual successors (Fig. 4D). Approximately $28 \%$ of the cells in population $\mathrm{D}$ contain dicentric chromosomes involving an amplified region. Figure 3D2 shows a dicentric chromosome in a tetraploid cell, again suggesting the occurrence of bridge/breakage/fusion cycles (McClintock 1941; Cowell and Miller 1983; Kaufman et al. 1983). Note that both striated and homogenous fluorescent staining were observed in the amplicon clusters in this population.

Population E At least 9 of the 18 cells examined in population E (Fig. 3E1,E2) carry amplified DHFR genes on chromosome $\mathrm{Z} 2$, again at a considerable distance from the parental single-copy locus (Figs. 3E1 and 4E). In half of the cells with an amplified region, it extends to the terminus of $\mathrm{Z} 2$. A relatively unusual tetraploid cell type is shown in Figure 3E2 in which amplicons are clustered on a chromosome tentatively identified as Z4. This arrangement could be the product of a bridge/ breakage/fusion cycle or translocation between $\mathrm{Z} 2$ and Z4.

Population F DHFR amplicon clusters appear on chro- 

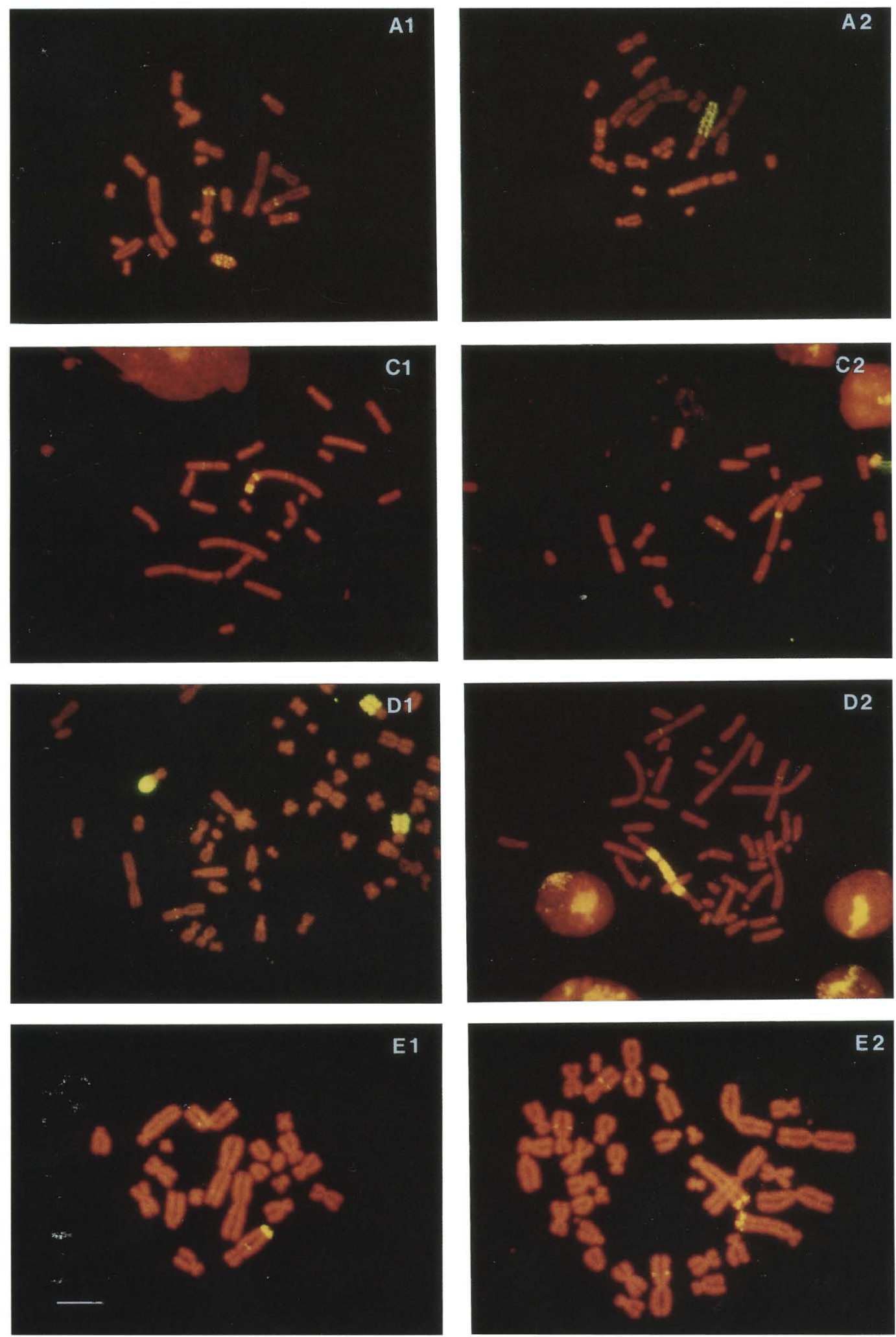

Figure 3. (See following page for legend.) 


\section{Trask and Hamlin}
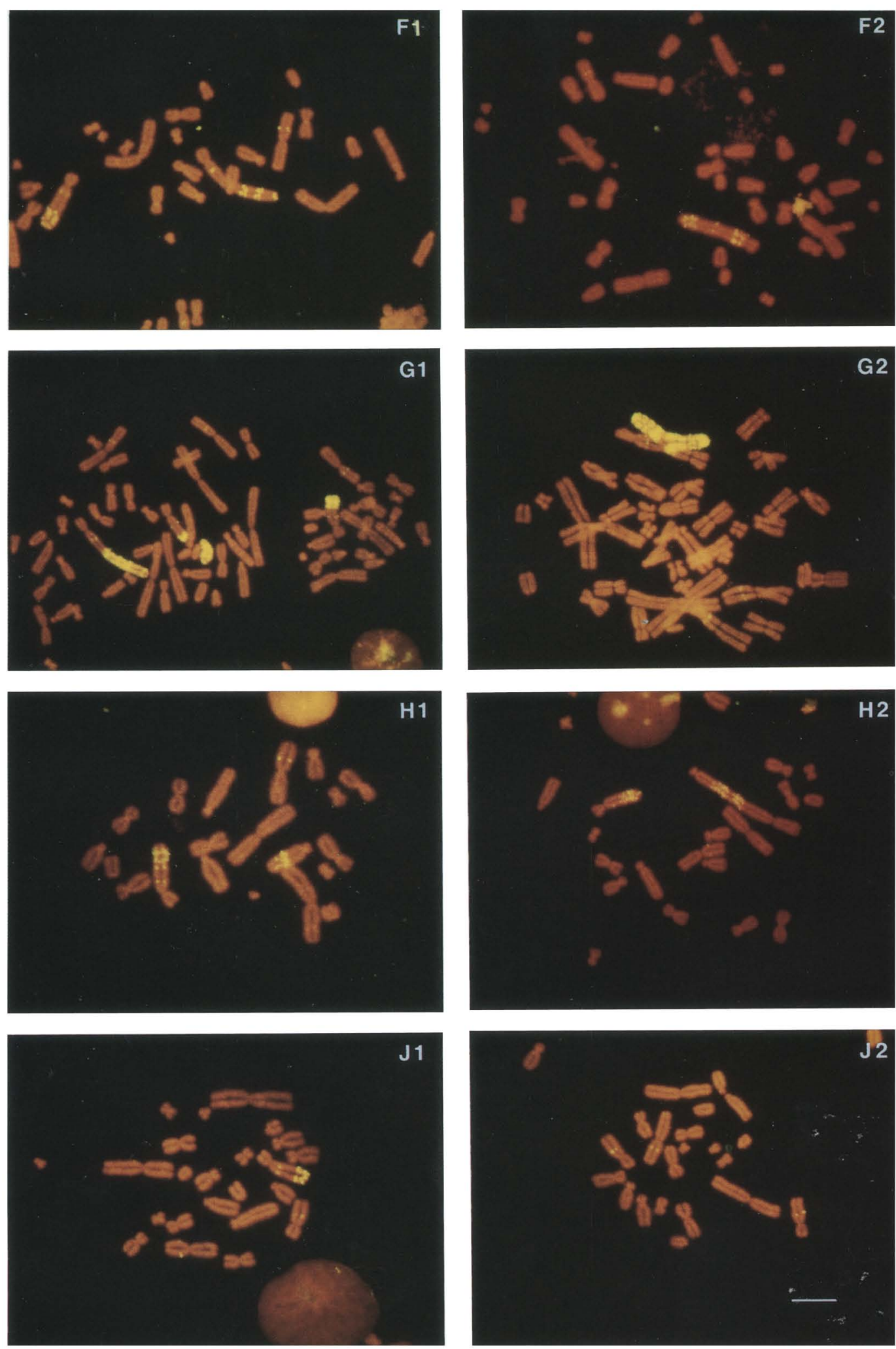

Figure 3. Two mitotic spreads from each of eight independently derived moderately MTX-resistant cell populations after fluorescence in situ hybridization with DHFR locus probes. (E1 and I2) Bar, $10 \mu \mathrm{m}$. 
Downloaded from genesdev.cshlp.org on April 26, 2023 - Published by Cold Spring Harbor Laboratory Press
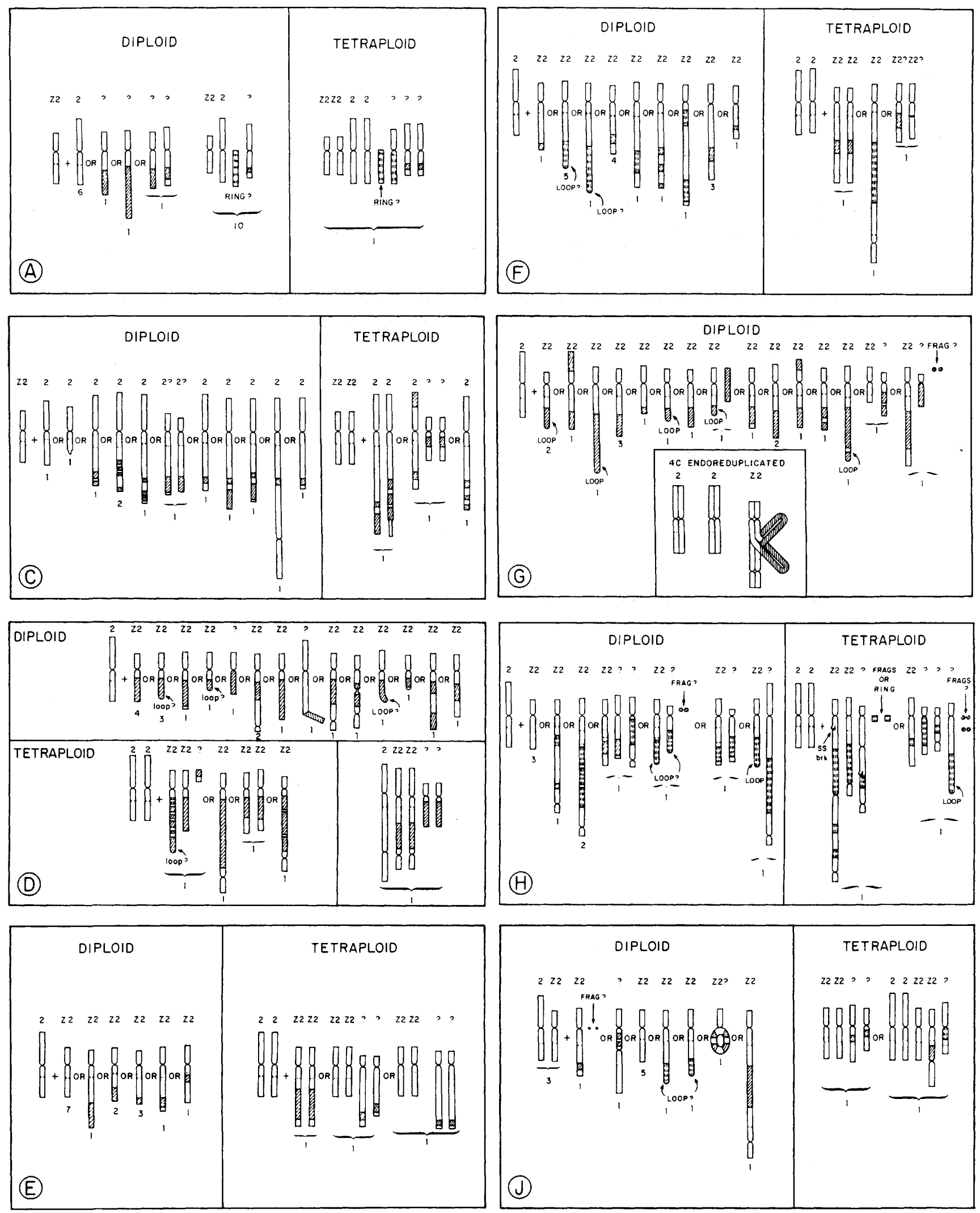

Figure 4. Positions of fluorescent signals after hybridization to DHFR locus cosmids in chromosomes from eight independently derived moderately MTX-resistant cell populations. The positions of single-copy sites and amplicon clusters were determined relative to centromeres and telomeres in randomly selected metaphase spreads in each population. The lengths of chromosomes in different spreads were normalized to each other using chromosome 2 as an internal standard. Paired dots indicate the positions of apparent single-copy sites. Uniformly staining amplicon clusters are indicated by diagonal hatching, and patchy, irregularly spaced fluorescent hybridization patterns are indicated by vertical hatching. The number of cells with a given hybridization pattern are indicated below the chromosomes. 
mosome $\mathrm{Z} 2$ at a terminal or near-terminal position in all but one cell examined in population $F$ (Fig. $3 F 1, F 2$ ), and both single-copy DHFR loci can be detected at their original positions. Portions of two different mitotic spreads are shown in Figure 3F1, which illustrate two commonly observed patterns of fluorescent staining in the distal region of chromosome $\mathrm{Z} 2$ in this population: patchy and striated. Figure $3 \mathrm{~F} 2$ shows a karyotype in which the Z2 chromosome appears to have suffered a duplication/inversion or insertion in which an additional amplicon cluster is now present between the centromere and the single-copy locus. A large, diffuse DHFR-specific chromosome fragment can also be seen in this mitotic cell.

Population $G$ The amplicon clusters are terminally located in $95 \%$ of the cells in population G (Fig. 3G1,G2). Figure 3G1 shows three different mitotic cells for one diploid and one tetraploid cell) that represent possible stages during the development of drug resistance. The spread on the right in Figure $3 \mathrm{G} 1$ has a single, terminal amplicon cluster on chromosome $\mathrm{Z2}, \sim 50 \mathrm{Mb}$ from the parental single-copy DHFR locus. The amplicon cluster appears to have elongated in the cell on the far left. In the cell in the center, the amplicon cluster appears to have broken off from chromosome $\mathrm{Z} 2$, yielding a fragment or ring chromosome. In the two metaphases on the left, the sister chromatids of chromosome $\mathrm{Z} 2$ are joined to form a loop. Figure 3G2 shows a very unusual endoreduplicated tetraploid cell (eight chromatids of each chromosome) in which the $\mathrm{Z} 2$ chromosome is undergoing a complex exchange. The fate of a cell with this karyotype is unknown.

Population $H$ Amplicon clusters are observed at a distance from the parental single-copy locus on $\mathrm{Z} 2$ in all amplificants in population $\mathrm{H}$ (Fig. $3 \mathrm{H} 1, \mathrm{H} 2$ ). In the cell shown in Figure $3 \mathrm{Hl}$, patchy amplicon clusters are flanked by what appears to be an additional single-copy locus on the centromere-proximal side of the cluster. In this cell, as in others in the population, a second amplicon cluster is located on another chromosome. A possible progenitor (or product) of this arrangement is shown in Figure $3 \mathrm{H} 2$, in which an unidentified chromosome (possibly $\mathrm{Z} 4$ ) is attached, end to end, to chromosome 1 , probably as the result of a bridge/breakage/fusion cycle. Small fragments hybridizing to the DHFRspecific probe were seen in three cells.

Population I The majority of cells in population J (Fig. $3 \mathrm{~J} 1, \mathrm{~J} 2$ ) display amplicon clusters distal to the single-copy
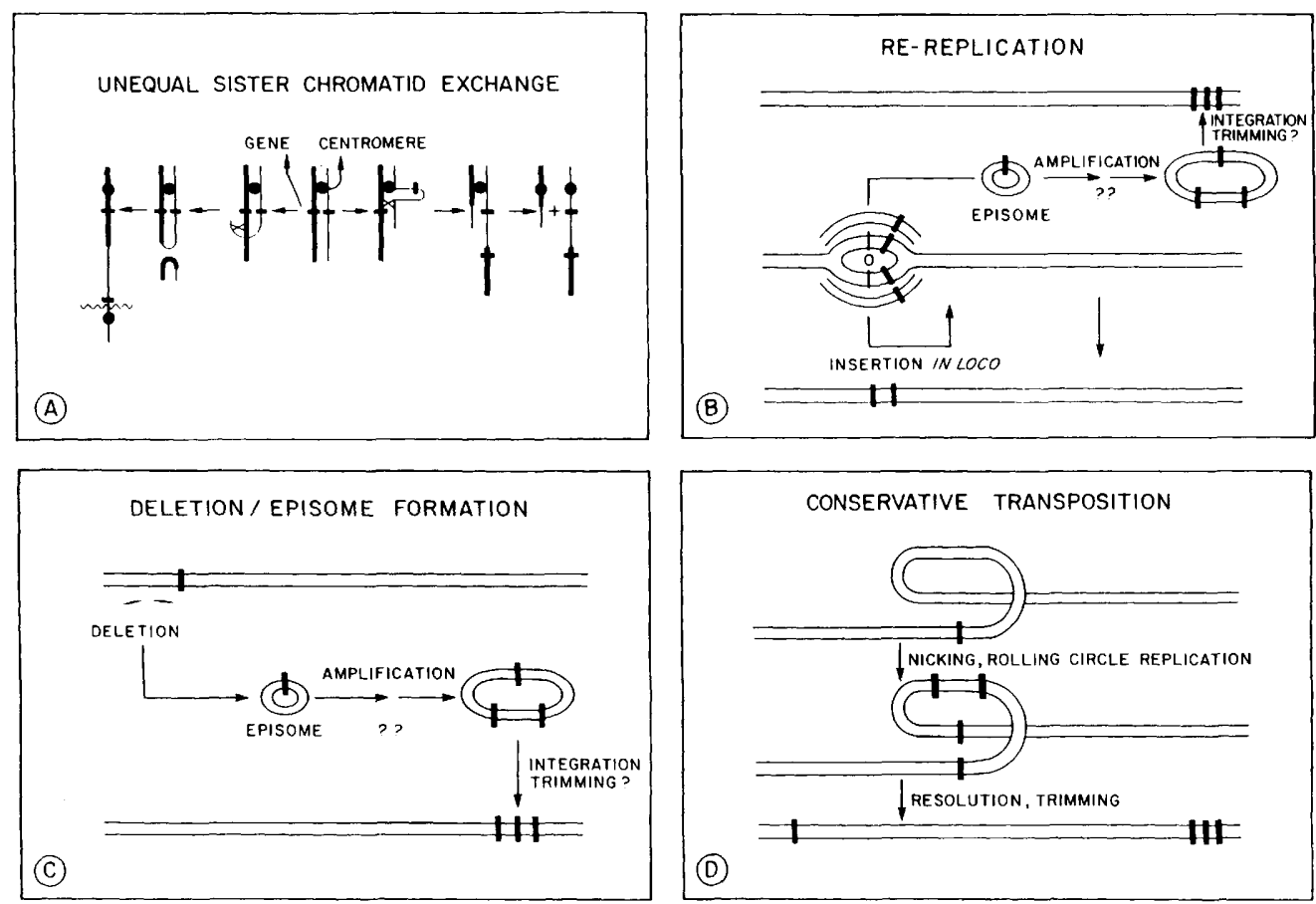

Figure 5. Models for initial amplification events in CHO cells. $(A)$ Two different unequal sister chromatid exchange events are pictured that would lead to an initial duplication of the DHFR gene. $(B)$ An over-replication model is pictured that would lead to amplification either in loco, if the extra duplexes were integrated close to the original locus, or at a distant position, if the extra duplexes had a finite extrachromosomal existence. The length of the amplicons may be shortened during the process. $(C)$ A deletion model in which the deleted locus forms an episome that increases in size and gene copy number, possibly by rolling-circle replication; the episome then either remains extrachromosomal or reintegrates into the same or another chromosome, possibly after having been trimmed. $(D)$ A conservative transposition model in which extra copies of the locus in question are generated by a roll-in replication mechanism analogous to transposition of bacteriophages but in which the original locus remains intact (Harshey and Bukhari 1981, Galas and Chandler 1981). 
locus on chromosome $\mathbf{Z} 2$. In addition, however, most of these amplificants retain apparently normal versions of both $\mathrm{Z} 2$ and 2 (Fig. $4 \mathrm{~J}$ ). In the example shown in Figure $3 J 1$, the two long chromatid arms appear to be fused at their termini. As discussed above, this fusion could give rise to the types of dicentric chromosomes observed in Figure $3 \mathrm{C} 2,3 \mathrm{D} 2$, and $3 \mathrm{H} 2$, discussed above. The cell in Figure 3/2 contains two copies of $\mathrm{Z} 2$ and one chromosome 2. It may have arisen from the cell type shown in Figure 3/1 by loss of the amplicon cluster through a fragmentation event. Alternatively, it may have been the progenitor cell in which an amplification event occurred on chromosome $\mathrm{Z} 2$ to give rise to the cell type shown in Figure 3J1.

\section{Discussion}

The results of the studies reported here are compatible with other investigations in which either G-banding or in situ hybridization with radiolabeled probes was used to determine the chromosomal locations of amplified sequences in MTX-resistant Chinese hamster cells (Biedler and Spengler 1976; Nunberg et al. 1978; Biedler et al. 1980; Kaufman and Schimke 1981; Milbrandt et al. 1981; Biedler 1982). As in the studies of Biedler and coworkers (Biedler and Spengler 1976; Biedler 1982), we observed a striking preference for amplification on one of the parental DHFR-bearing chromosomes in Chinese hamster cells (the $\mathrm{MK} 42, \mathrm{~A} 3 / 4 \mathrm{~K}$, and $\mathrm{B} 11-0.5 \mathrm{~K} 1$ cell clones and at least seven of the eight moderately resistant populations that contain amplificants).

However, the increased sensitivity and resolution of the fluorescence detection method have allowed us to define the positions, boundaries, and fine structure of amplicon clusters with greater precision than is possible in hybridization studies employing radiolabeled probes. More importantly, the method has allowed us to make several additional observations on the early products of DNA sequence amplification in $\mathrm{CHO}$ cells that were not possible with previous techniques. In particular, we detected both single-copy loci in their characteristic positions in almost all of the amplificants and could measure the distance between the single-copy locus and the closest amplicon cluster on the same chromosome arm.

In spite of the apparent diversity both within and among the nine moderately resistant populations examined here, several important generalizations can be made.

1. DNA sequence amplification appears to be the most common mode of acquiring drug resistance under our selection conditions (eight of nine populations). This finding agrees with the results of several other studies (Kaufman and Schimke 1981; Varshavsky 1981; Ardeshir et al. 1983; Barsoum and Varshavsky 1983; Brown et al. 1983; Zieg et al. 1983; Tlsty et al. 1984; Giulotto et al. 1986). Only in population B did all cells appear to contain just the single-copy DHFR loci. However, we also observed cells with apparently normal karyotypes in some of the populations in which DHFR amplification predominates as the mode of drug resistance [e.g., A $(6 / 20)$, C (1/15), E (7/17), $\mathrm{H}(3 / 12)$, and $\mathrm{J}(3 / 16)]$. Mutations in the DHFR enzyme or in a transport protein may therefore also have occurred in some of these cells.

2. There is a bias in this experiment toward amplification of the DHFR locus on chromosome Z2. In the eight populations in which amplification could be detected, amplicon clusters occur on $\mathrm{Z} 2$ in six (populations $\mathrm{D}, \mathrm{E}, \mathrm{F}, \mathrm{G}, \mathrm{H}$, and $\mathrm{J}$, on chromosome 2 in one (population $\mathrm{C}$ ), and on an unidentified chromosome (possible Z2) in one (population A). Although the sample number is small, it is formally possible that the previous rearrangements that gave rise to the altered Z2 chromosome (Deaven and Peterson 1973) may predispose this chromosome to DNA sequence amplification events. No cells were observed in any population that contained visible double minute chromosomes, although small fragments were seen in several cells in populations $\mathrm{G}, \mathrm{H}$, and J (Fig. 4).

3. DHFR amplicon clusters most often occur on the same chromosome arm as one of the parental loci, but at a considerable distance from it (seven of eight amplificants). The amplicon clusters are usually at least $50 \mathrm{Mb}$ from the single-copy locus and are often at or near the terminus. Furthermore, the distance from the single-copy DHFR locus to the nearest amplicon cluster is often greater than the distance between the single-copy locus and the terminus of the unaffected homolog. Cells in which amplicon clusters could be detected on other chromosomes were relatively infrequent. The latter could usually be explained as products of chromosome breakage or as translocations from chromosomes $\mathrm{Z} 2$ or 2 resulting from bridge/breakage/fusion cycles.

4. The single copy locus could be detected at its original chromosomal position in all but one example of amplification on chromosome $\mathrm{Z} 2$ or 2. The amplificants in populations $C, E, F, G, H$, and $J$ all retain the parental locus on the chromosome arm bearing the amplicon clusters. Even in the cell on the right in Figure 4A (culture A), the amplicon cluster may have broken off from $\mathrm{Z} 2$ to form the marker, again leaving the single-copy locus intact. Only in culture D and in B11-0.5K1 cells does amplification appear to have occurred in loco or close to the single-copy site.

5. Several intermediates in bridge/breakage/fusion cycles were observed. Chromosome rearrangements were detected that suggest the occurrence of the classical bridge/breakage/fusion cycles originally observed in maize (McClintock 1941) and, more recently, in cells carrying amplified genes (Cowell and Miller 1983; Kaufman et al. 1983). The postulated intermediates in this process (dicentrics and chromosomes in which sister chromatids are fused at their termini) were observed at a high frequency in the eight populations containing amplificants 120 and 18 of the 120 karyotypes exhibiting amplification, respectively; see Fig. 3C2, D2, G1, G2, H2, J1). These intermediates may explain why amplicon clusters are 
often located at the termini of chromosomes, if it is assumed that the dicentric bridge chromosomes usually break within the amplicon cluster during anaphase. Furthermore, the broken end thus generated can be healed by attachment to other chromosomes, which themselves contain centromeres. This would initiate other bridge/breakage/fusion cycles (as suggested, e.g., by the karyotype in Fig. 3H2).

6. Amplicon clusters have a patchy appearance in some low-level amplificants. We used hybridization probes for $\sim 273 \mathrm{~kb}$ of contiguous DNA sequence in this study. Therefore, this result suggests that early amplicons can be considerably greater than $273 \mathrm{~kb}$; i.e., the nonhybridizing sequences between clusters may also be part of the amplification unit (e.g., as in Fig. 3F1). There is considerable experimental evidence for extremely large amplicons in the early stages of amplification in hamster cells (Giulotto et al. 1986; Ma et al. 1988; Saito et al. 1989). However, the more uniform staining of amplicon clusters in the highly MTX-resistant cell lines pictured in Figure 2, as well as in some of the lower level amplificants (see Fig. 3), indicates that the amplicons in these cell lines may have become trimmed to a smaller average length during amplification, as has been suggested previously (Ardeshir et al. 1983; Zieg et al. 1983; Federspiel et al. 1984; Ma et al. 1988).

The results of our studies do not allow us to make definitive conclusions about the mechanisms that operate during the initial stages of DNA sequence amplification. First, we have not examined initial events here. Many cells had already undergone multiple rounds of amplification, as well as subsequent translocation events, by the time they were resistant to $0.4 \mu \mathrm{M}$ MTX. Second, our data are consistent with several different and quite disparate models for DNA sequence amplification in mammalian cells. However, our results must be accommodated by any tenable model for sequence amplification in Chinese hamster cells.

The most popular models for DNA sequence amplification fall into three general categories (Hamlin et al. 1984; Schimke 1984, 1988; Stark and Wahl 1984; Stark 1986; Wahl 1989|: (1) Unequal recombination models (Fig. 5A) suggest that one chromatid receives an additional copy of a large sequence through an unequal sister chromatid exchange event, which results in the gain by one chromatid and the loss by the other of the DNA sequence in question; (2) rereplication models (Fig. 5B) suggest that extra rounds of replication occur at a particular locus in a single cell cycle; the extra daughter duplexes become integrated in tandem arrays either in the body of the chromosome or as extrachromosomal double minutes; (3) a deletion/episome model has recently been suggested in which the locus in question is deleted from the chromosome and has an extended existence as a submicroscopic episome that increases in size, possibly by rolling-circle replication (Fig. 5C; Wahl 1989). The episome could finally become recognizable as a microscopically visible double minute chromosome or could reintegrate into a chromosome, conferring stability to the resistant phenotype.

Our finding that the amplicon clusters are usually located $>50 \mathrm{Mb}$ away from the original single-copy locus is not compatible with the rereplication model in which the extra daughter duplexes are integrated in loco /Fig. 5B). Models that substitute rolling-circle in loco replication are also largely eliminated by this finding. Our observations are also difficult to reconcile with the model involving deletion of a parental DHFR locus, subsequent amplification during a sustained extrachromosomal existence, and possible reintegration (Wahl 1989). The overwhelming majority of amplicon clusters in the cell lines studied here are located on the same arm as one of the parental loci. This finding requires that the episome would usually have to reintegrate into the chromosome from which it was derived after its autonomous existence. This could be a likely occurrence if chromosomes occupy their own intranuclear domains or compartments (Cremer et al. 1982; Lichter et al. 1988; Pinkel et al. 1988). However, if that were the case, we would have expected to observe many cells in which the amplicon clusters were located either on the $p$ arm of chromosome $\mathrm{Z} 2$ or 2 or nearer the centromere and the single-copy site of the $q \mathrm{arm}$. In fact, extremely few of these patterns were detected (Figs. 3 and 4).

The observation that both single-copy DHFR loci were found intact at their original locations (i.e., not deleted) in all but a few cells might also appear to rule out episome formation as a possible primary event in DNA sequence amplification in $\mathrm{CHO}$ cells. However, if deletion and episome formation were to occur after DNA replication but prior to mitosis, then a cell that received both parental single-copy loci, as well as the episome itself, may survive selection on MTX.

We believe that our data are most consistent with two other models for initial amplification events. The observation that $D H F R$ amplicon clusters are located on the same chromosome arm as a parental DHFR locus in at least seven of the eight populations of low-level amplificants and at least three out of four highly resistant clones suggests that initial amplification events are intrachromosomal (even intra-arm) in nature. This could result from at least two different mechanisms.

In unequal sister chromatid exchange, a nonhomologous recombination event might occur if the end of the $\mathrm{Z} 2$ chromosome were to loop around to contact the region of the $2 q$ arm on the opposite sister chromatid in either of the two configurations pictured in Figure 5A. The exchange pictured on the left would result in a dicentric, which would eventually have to break between the gene and the centromere to yield a stable duplication. We have no compelling explanations for how the amplicon copy number might increase after either of the initial unequal exchange events pictured in Figure 5. However, it is conceivable that either the large direct or inverted repeats and/or the unnatural junctions thus generated could render subsequent unequal exchanges (or other rearrangement) more likely.

Alternatively, conservative transposition, as occurs in 
bacteria (Harshey and Bukhari 1981; Galas and Chandler 1981), could explain the presence of amplicon clusters at a distance from the original single-copy site on the same chromosome, as outlined in Figure $5 \mathrm{D}$. The singlestrand nicks that are found at telomeres (Blackburn 1984) could provide one-half of the initiation reaction required by this mechanism, accounting for the high frequency of amplicon clusters located at telomeric positions. The rolling-circle amplification step involved in this model could also explain the rapid appearance of large copy numbers of the amplified sequence during drug selection, as termination could sometimes occur only after many rounds of replication have proceeded around the circle (Fig. 5D).

Deciding among the several models for DNA sequence amplification will require high resolution chromosome and sequence analysis of much earlier intermediates in the amplification process, and studies of this nature are presently under way in our laboratories. It will also be important to devise a selection scheme that allows the recovery of all of the products of the first amplification events. In particular, it would be useful to isolate cells carrying the chromosomes that are postulated to delete the DHFR locus in either the unequal sister chromatid exchange or episome/deletion models for amplification, so that the proposed compensatory deletion/amplification rearrangements could be ascertained.

\section{Experimental methods}

\section{Cell culture and selection procedures}

The CHOC 400, A3/4K, MK42, and B11-0.5Kl cell lines were developed and maintained as described previously (Biedler and Spengler 1976; Nunberg et al. 1978; Kaufman and Schimke 1981; Milbrandt 1981). The nine moderately resistant cell lines analyzed in this study were selected as follows: A single CHO-K1 cell was cloned and expanded to $\sim 10^{7}$ cells, and $2.5 \times 10^{5}$ cells were then seeded into each of nine $100-\mathrm{mm}$ plates; selection on $0.02 \mu \mathrm{M}$ MTX was applied $24 \mathrm{hr}$ after plating. Most cells were not killed at this drug level in this experiment (possibly because this MTX preparation was not as potent as those employed in previous studies), and no amplification was detected in the populations surviving 2 weeks of selection by fluorescence hybridization (data not shown). Therefore, after 2 weeks, the cells were subjected to $0.1 \mu \mathrm{M}$ MTX. After 2 weeks more, the surviving cells were subjected to $0.4 \mu \mathrm{M}$ MTX for an additional 2 weeks. The total elapsed time between initial exposure to $0.1 \mu \mathrm{M}$ MTX and in situ hybridization analysis was $\sim 6$ weeks.

\section{In situ hybridization with biotinylated cosmid probes}

Cultures were incubated with $0.1 \mu \mathrm{g}$ colcemid per milliliter of medium for $1.5 \mathrm{hr}$, and mitotic cells were collected by shakeoff. The cells were swollen for $15 \mathrm{~min}$ in $75 \mathrm{mM} \mathrm{KCl}$ at $37^{\circ} \mathrm{C}$, fixed in fresh methanol/acetic acid $(3: 1)$, and dropped onto microscope slides.

Cosmid DNA was biotinylated by nick translation (Rigby et al. 1977) with biotin-11-dUTP (Bethesda Research Laboratories). Biotinylated cosmid DNAs were pooled at a concentration of $\sim 20 \mathrm{ng} / \mu \mathrm{l}$, and probes were hybridized to cells at $37^{\circ} \mathrm{C}$ overnight as described previously (Pinkel et al. 1986; Trask et al. 1989). The hybridization mixture consisted of $50 \%$ formamide,
$2 \times$ SSC, $10 \%$ dextran sulfate, and $2 \mathrm{ng} / \mu \mathrm{l}$ of pooled probes. Sonicated Chinese hamster genomic DNA (200-600 bp in length) was added to the hybridization mixture at a final concentration of $I \mu \mathrm{g} / \mu \mathrm{l}$ to suppress hybridization of repetitive sequences in the probes. After washing, avidin conjugated to fluorescein (DCS, Vector Laboratories) was applied at $5 \mu \mathrm{g} / \mathrm{ml}$ as described previously (Pinkel et al. 1986). In some cases (Fig. $3 \mathrm{~A} 1$ ), the fluorescence signal was further amplified by incubating the slides in biotin-conjugated goat anti-avidin $(5 \mu \mathrm{g} / \mathrm{ml}$, Vector Laboratories), followed by incubation in avidin-fluorescein isothiocyanate (FITC). Propidium iodide was applied to the slides at $0.5 \mu \mathrm{g} / \mathrm{ml}$ in a fluorescence anti-fade solution (Johnson and Nogueria 1981). Color slides of randomly selected cells were taken using a Zeiss Axiophot microscope equipped with a Zeiss Plan Neofluor oil immersion objective (100×, 1.3 numerical aperture) and a $1.25 \times$ optivar, using Kodak Ektachrome 400 transparency film and 45- to 90-sec exposures. Epifluorescence filters were as follows: excitation, BP485 nm; reflector, $510 \mathrm{~nm}$; emission, LP 520.

Chromosome length, centromeric index, and the positions of single-copy sites and amplicon clusters were determined from projected slide images. The lengths of the chromosomes displaying fluorescence hybridization signals (diagrammed in Fig. 4) were normalized to the length of chromosome 2 in each metaphase. A summary of all cells photographed is presented in Figure 4. The original photographs are available on loan to anyone interested in analyzing them further.

\section{Acknowledgments}

We thank our technicians Carlton White, Kevin Cox, and Charlotte Lozes for dedicated assistance in all aspects of this project. We also thank Bill Pearson (University of Virginia) for valuable discussions. Larry Chasin, June Biedler, and Bob Schimke kindly provided the MK42, A3, and B11-0.5K1 cell lines, respectively. This work was supported by a grant from the American Cancer Society to J.L.H. (CD298). The work at Lawrence Livermore National Laboratory was performed under the auspices of the U.S. Department of Energy (contract W-7405-ENG-48).

\section{References}

Alitalo, D. and M. Schwab. 1985. Oncogene amplification in tumor cells. Adv. Cancer Res. 47: 235-281.

Anachkova, B. and J.L. Hamlin. 1989. Replication in the amplified dihydrofolate reductase domain in CHO cells may initiate at two distinct sites, one of which is a repetitive element. Mol. Cell. Biol. 9: 532-540.

Ardeshir, F., E. Giulatto, J. Zieg, O. Brison, W.S.L. Liav, and G.R. Stark. 1983. Structure of amplified DNA in different Syrian hamster cell lines resistant to $\mathrm{N}$-(phosphonacetyl)-Laspartate. Mol. Cell. Biol. 3: 2076-2088.

Barker, P.E. 1982. Double minutes in human tumor cells. Cancer Genet. Cytogenet. 5: 81-94.

Barsoum, J. and A. Varshavsky. 1983. Mitogenic hormones and tumor promoters greatly increase the incidence of colonyforming cells bearing amplified dihydrofolate reductase. Proc. Natl. Acad. Sci. 80: 5330-5334.

Biedler, J.L. 1982. Evidence for transient existence of amplified DNA sequences in antifolate-resistant, vincristine-resistant and human neuroblastoma cells. In Gene amplification (ed. R.T. Schimkel, pp. 39-45. Cold Spring Harbor Laboratory, Cold Spring Harbor, New York.

Biedler, J.L. and B.A. Spengler. 1976. A novel chromosome ab- 
normality in human neuroblastoma and antifolate-resistant Chinese hamster cells in culture. J. Natl. Cancer Inst. 57: 683-695.

Biedler, J.L., P.W. Melera, and B. Spengler. 1980. Specifically altered metaphase chromosomes in antifolate-resistant Chinese hamster cells that overproduce dihydrofolate reductase. Cancer Genet. Cytogenet. 2: 47-60.

Bishop, J.M. 1987. The molecular genetics of cancer. Science 235: 305-311.

Blackburn, E.H. 1984. Telomeres: Do the ends justify the means? Cell 37: 7-8.

Borst, P., A.M. Van der Bliek, T. Van Der Velde-Koerts, and E. Hes. 1987. Structure of amplified DNA, analyzed by pulse field gradient gel electrophoresis. J. Cell. Biochem. 34: 247258.

Brown, P.C., T.D. Tlsty, and R.T. Schimke. 1983. Enhancement of methotrexate resistance and dihydrofolate reductase gene amplification by treatment of mouse 3T6 cells with hydroxyurea. Mol. Cell. Biol. 3: 1097-1107.

Caizzi, F. and C.J. Bostock. 1982. Gene amplification in methotrexate-resistant mouse cells. IV. Different DNA sequences are amplified in different resistant lines. Nucleic Acids Res. 10: $6597-6618$.

Carroll, S.M., P. Gaudray, M.L. Derose, J.F. Emery, J.L. Meinkoth, E. Nakkim, M. Subler, D.D. Von Hoff, and G.M. Wahl. 1987. Characterization of an episome produced in hamster cells that amplify a transfected CAD gene at high frequency: Functional evidence for a mammalian replication origin. Mol. Cell. Biol. 7: 1740-1750.

Cowell, J.K. 1982. Double minutes and homogeneously staining regions: Gene amplification in mammalian cells. Annu. Rev. Genet. 16: 21-59.

Cowell, J.K. and O.J. Miller. 1983. Occurrence and evolution of homogeneously staining regions may be due to breakage-fusion-bridge cycles following telomere loss. Chromosoma 88: $216-221$.

Cremer, T., C. Cremer, T. Schneider, H. Baumann, L. Hens, and M. Kirsch-Volders. 1982. Analysis of chromosome positions in the interphase nucleus of Chinese hamster cells by laserUV-microirradiation experiments. Hum. Genet. 62: 210209.

Deaven, L.L. and D.F. Peterson. 1973. The chromosomes of $\mathrm{CHO}$, an aneuploid Chinese hamster cell line: G-band, Cband, and autoradiographic analyses. Chromosoma 41: $129-144$.

Debatisse, M., O. Hyrien, E. Petit-Koskas, R. de Saint Vincent, and G. Buttin. 1986. Segregation and rearrangement of coamplified genes in different lineages of mutant cells that overproduce adenylate deaminase. Mol. Cell. Biol. 6: 17761781 .

Dijkwel, P.A. and J.L. Hamlin. 1988. Matrix attachment regions are positioned near replication initiation sites, genes, and an interamplicon junction in the amplified dihydrofolate reductase domain in Chinese hamster ovary cells. Mol. Cell. Biol. 8: 5398-5409.

Federspiel, N.A., S.M. Beverley, J.W. Schilling, and R.T. Schimke. 1984. Novel DNA rearrangements are associated with dihydrofolate reductase gene amplification. $J$. Biol. Chem. 259: 9127-9140.

Foreman, P.K. and Hamlin, J.L. 1989. Identification and characterization of a gene that is co-amplified with dihydrofolate reductase in a methotrexate-resistant $\mathrm{CHO}$ cell line. Mol. Cell. Biol. 9: 1137-1147.

Funanage, V.L. and T.T. Myoda. 1986. Localization of the Chinese hamster dihydrofolate reductase gene to band p23 of chromosome 2. Somatic Cell Mol. Genet. 12: 649-655.
Galas, D.J. and M. Chandler. 1981. On the molecular mechanism of transposition. Proc. Natl. Acad. Sci. 78: 4858-4862.

Giulotto, E., I. Saito, and G.R. Stark. 1986. Structure of DNA formed in the first step of CAD gene amplification. EMBO $\%$. 5: 2115-2121.

Hamlin, J.L., J.D. Milbrandt, N.H. Heintz, and J.C. Azizkhan. 1984. DNA sequence amplification in mammalian cells. Int. Rev. Cytol. 90: 31-82.

Harshey, R.M. and A.I. Bukhari. 1981. A mechanism of DNA transposition. Proc. Natl. Acad. Sci. 78: 1090-1094.

Heintz, N.H. and J.L. Hamlin. 1982. An amplified chromosomal sequence that includes the gene for dihydrofolate reductase initiates replication within specific restriction fragments. Proc. Natl. Acad. Sci. 79: 4083-4087.

Hyrien, O., M. Debatisse, G. Buttin, and B.R. de Saint Vincent. 1987. A hotspot for novel amplification joints in a mosaic of Alu-like repeats and palindromic A + T-rich DNA. EMBO I. 6: 2401-2408.

Johnson, G.D. and J.G.M. Nogueria. 1981. A simple method of reducing the fading of immunofluorescence during microscopy. I. Immunol. Methods 43: 349-350.

Johnston, R.N., S.M. Beverley, and R.T. Schimke. 1983. Rapid spontaneous dihydrofolate reductase gene amplification shown by fluorescence activated cell sorting. Proc. Natl. Acad. Sci. 80: 3711-3715.

Kaufman, R.J. and R.T. Schimke. 1981. Amplification and loss of dihydrofolate reductase genes in a Chinese hamster ovary cell line. Mol. Cell. Biol. 1: 1069-1076.

Kaufman, R.L., P.A. Sharp, and S.A. Latt. 1983. Evolution of chromosomal regions containing transfected and amplified dihydrofolate reductase sequences. Mol. Cell. Biol. 3: 699711.

Kinzler, K.W., B.A. Zehnbauer, G.M. Brodeur, R.C. Seeger, J.M. Trent, P.S. Meltzer, and B. Vogelstein. 1986. Amplification units containing human n-myc and c-myc genes. Proc. Natl. Acad. Sci. 83: 1031-1035.

Lavi, S. 1981. Carcinogen-mediated amplification of viral DNA sequences in SV40-transformed Chinese hamster embryo cells. Proc. Natl. Acad. Sci. 78: 6144-6148.

Leu, T.-H. and J.L. Hamlin. 1989. High resolution mapping of replication fork movement through the amplified dihydrofolate reductase domain in $\mathrm{CHO}$ cells by in-gel renaturation analysis. Mol. Cell. Biol. 9: 523-531.

Levan, A., G. Levan, and F. Mitelman. 1977. Chromosomes and cancer. Hereditas 86: 15-29.

Lichter, P., T. Cremer, J. Borden, L. Manuelidis, and D.C. Ward. 1988. Delineation of individual human chromosomes in metaphase and interphase cells by in situ suppression hybridization using recombinant DNA libraries. Hum. Genet. 80: $224-234$.

Looney, J.E. and J.L. Hamlin. 1987. Isolation of the amplified dihydrofolate reductase domain from methotrexate-resistant Chinese hamster ovary cells. Mol. Cell. Biol. 7: 569577.

Looney, J.E., C. Ma, T.-H. Leu, W.F. Flintoff, W.B. Troutman, and J.L. Hamlin. 1988. The DHFR amplicons in different MTX-resistant Chinese hamster cell lines share at least a 273-kilobase core sequence, but the amplicons in some cell lines are much larger and are remarkably uniform in structure. Mol. Cell. Biol. 8: 5268-5279.

Ma, C., J.E. Looney, T.-H. Leu, and J.L. Hamlin. 1988. Organization and genesis of dihydrofolate reductase amplicons in the genome of a methotrexate-resistant Chinese hamster ovary cell line. Mol. Cell. Biol. 8: 2316-2327.

McClintock, B. 1941. The stability of broken ends of chromosomes in Zea mays. Genetics 26: 234-282. 
Milbrandt, J.D., N.H. Heintz, W.C. White, S.M. Rothman, and J.L. Hamlin. 1981. Methotrexate-resistant $\mathrm{CHO}$ cells have amplified a 135 kilobase region that includes the dihydrofolate reductase gene. Proc. Natl. Acad. Sci. 78: 6043-6047.

Nunberg, J.H., R.J. Kaufman, R.T. Schimke, G. Urlaub, and L.A. Chasin. 1978. Amplified dihydrofolate reductase genes are localized to a homogeneously staining region of a single chromosome in a methotrexate-resistant Chinese hamster ovary cell line. Proc. Nat1. Acad. Sci. 75: 5553-5556.

Pinkel, D., T. Straume, and J.W. Gray. 1986. Cytogenetic analysis using quantitative, high-sensitivity, fluorescence hybridization. Proc. Natl. Acad. Sci. 83: 2934-2938.

Pinkel, D., J. Landegent, C. Collins, J. Fuscoe, R. Segraves, J. Lucas, and J. Gray. 1988. Fluorescence in situ hybridization with human chromosome-specific libraries: Detection of trisomy 21 and translocations of chromosome 4. Proc. Natl. Acad. Sci. 85: 9138-9142.

Rigby, P.W.J., M. Dieckmann, C. Rhodes, and P. Berg. 1977. J. Mol. Biol. 113: 237-251.

Roninson, I.B., H.T. Abelson, D.E. Housman, N. Howell, and A. Varshavsky. 1984. Amplification of specific DNA sequences correlates with multi-drug resistance in Chinese hamster cells. Nature 309: 626-628

Saito, I., R. Groves, E. Giulotto, M. Rolfe, and G.R. Stark. 1989. Evolution and stability of chromosomal DNA coamplified with the CAD gene. Mol. Cell. Biol. 9: 2445-2452.

Schimke, R.T. 1984. Gene amplification, drug-resistance, and cancer. Cancer Res. 44: 1735-1742.

- 1988. Gene amplification in cultured cells. J. Biol. Chem. 263: 5989-5992.

Stark, G.R. 1986. DNA amplification in drug-resistant cells and in tumors. Cancer Surv. 5: 1-23.

Stark, G.R. and G.M. Wahl. 1984. Gene amplification. Annu. Rev. Biochem. 53: 447-491.

Tlsty, T.D., P.C. Brown, and R.T. Schimke. 1984. UV radiation facilitates methotrexate resistance and amplification of the dihydrofolate reductase gene in cultured 3T6 mouse cells. Mol. Cell. Biol. 6: 1050-1056.

Trask, B.J., D. Pinkel, and G. van den Engh. 1989. The proximity of DNA sequences in interphase cell nuclei is correlated to genomic distance and permits ordering of cosmids spanning 250 kilobase pairs. Genomics 5: 710-717.

Tyler-Smith, C. and C.J. Bostock. 1981. Gene amplification in methotrexate-resistant mouse cells. III. Interrelationships between chromosome changes and DNA sequence amplification or loss. J. Mol. Biol. 153: 237-256.

Van der Bliek, A.M., T. Van der Velde-Koerts, V. Ling and P. Borst. 1986. Overexpression and amplification of five genes in a multidrug-resistant Chinese hamster ovary cell line. Mol. Cell. Biol. 6: 1671-1678.

Varshavsky, A. 1981. Phorbol ester dramatically increases incidence of methotrexate-resistant colony-forming mouse cells: Possible mechanisms and relevance to tumor promotion. Cell 25: 561-572.

Wahl, G.M. 1989. The importance of circular DNA in mammalian gene amplification. Cancer Res. 49: 1333-1340.

Worton, R.G. 1978. Karyotypic heterogeneity in CHO cell lines. Cytogenet. Cell Genet. 21: 105-110.

Yunis, J.L. 1981. Specific fine chromosomal defects in cancer: An overview. Hum. Pathol. 120: 503-515.

Zieg, J., C.E. Clayton, F. Ardeshir, E. Giulotto, E.A. Swyryd, G.R. Stark. 1983. Properties of single-step mutants of Syrian hamster cell lines resistant to N-phosphonacetyl-L-aspartate. Mol. Cell. Biol. 3: 2089-2098. 


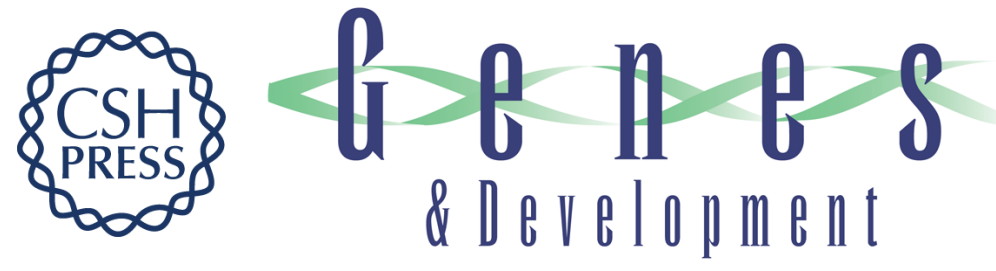

\section{Early dihydrofolate reductase gene amplification events in $\mathrm{CHO}$ cells usually occur on the same chromosome arm as the original locus.}

B J Trask and J L Hamlin

Genes Dev. 1989, 3:

Access the most recent version at doi:10.1101/gad.3.12a.1913

References This article cites 61 articles, 33 of which can be accessed free at:

http://genesdev.cshlp.org/content/3/12a/1913.full.html\#ref-list-1

License

Email Alerting

Service

Receive free email alerts when new articles cite this article - sign up in the box at the top right corner of the article or click here.

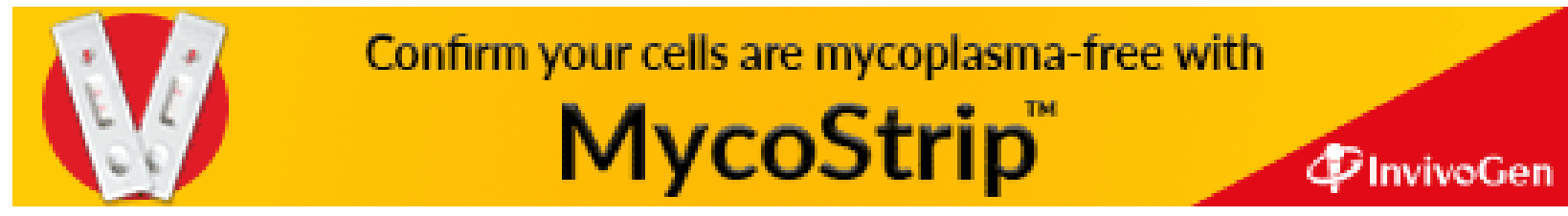

